\title{
CAPÍTULO 08: BACTÉRIAS DA MASTITE SUBCLÍNICA BOVINA: SUSCETIBILIDADE A ANTIBIÓTICOS
}

\section{CHAPTER 08: BACTERIA OF SUBCLINICAL MASTITIS: SUSCEPTIBILITY TO ANTIBIOTICS}

Pedro Rassier dos Santos ${ }^{1}$; Helenice de Lima Gonzalez ${ }^{2}$; Silvia Regina Leal Ladeira ${ }^{3}$ Ginini Carla Dors ${ }^{4}$; Patrícia da Silva Nascente ${ }^{5}$

\begin{abstract}
Resumo
O leite é um alimento de alto valor nutritivo e sua produção está presente no mundo todo, graças ao retorno rápido que ele possibilita ao produtor. Para que o leite e seus derivados não percam a qualidade, são necessários cuidados durante todo o processo. Salienta-se que o uso de antibióticos é comum nas propriedades para tratar a principal doença que acomete os bovinos leiteiros: a mastite. Com isso, o objetivo deste estudo foi testar a suscetibilidade de bactérias isoladas em casos de mastite subclínica frente a três antibióticos de uso na medicina veterinária. As bactérias foram isoladas de amostras de leite colhidas em diferentes propriedades rurais do município de Pelotas - RS e estocadas em laboratório. O antibiograma foi realizado com três antibióticos: Amoxicilina + ácido Clavulânico, Gentamicina e Tetraciclina. As bactérias estudadas foram Staphylococcus spp. (coagulase negativa), Staphylococcus spp. (coagulase positiva), Corynebacterium spp. e Streptococcus spp. A maior resistência foi observada à Gentamicina $(37,1 \%)$, seguido pela tetraciclina $(22,2 \%)$ e amoxicilina + ácido clavulânico $(18,5 \%)$. Esses resultados salientam para a identificação do agente causador de mastite e avaliação da eficácia dos antibióticos em cada propriedade, pois o uso indiscriminado de antibióticos vem aumentando a resistência dos microrganismos.
\end{abstract}

Palavras-Chaves: bovinos, CMT, produção leiteira, qualidade do leite, resistência.

\begin{abstract}
Milk is a high nutritional value food and has a worldwide production thanks to the rapid return it provides to producers. In order to milk and its derivatives not lose quality, some procedures are necessary, ranging from production to storage. It should be noted that the use of antibiotics is common in properties to treat the main disease that affects dairy cattle: mastitis. The aim of this study was to test the susceptibility of bacteria isolated in cases of subclinical mastitis against three antibiotics used in veterinary medicine. The bacteria were isolated from milk samples collected in different rural properties in the municipality of Pelotas - RS and stored in the laboratory. The antibiogram was performed with three antibiotics: Amoxicillin + Clavulanic acid, Gentamicin and Tetracycline. The bacteria studied were Staphylococcus spp. (coagulase negative), Staphylococcus spp. (positive coagulase), Corynebacterium spp. and Streptococcus spp. The highest resistance was observed to Gentamicin $(37.1 \%)$, followed by tetracycline (22.2\%) and amoxicillin + clavulanic acid (18.5\%). The results emphasize for the identification of the causative agent of mastitis and evaluation of the efficacy of antibiotics in each property, because the indiscriminate use of antibiotics has been increasing the resistance of microorganisms.
\end{abstract}

\footnotetext{
${ }^{1}$ Ciências Biológicas, Universidade Federal de Pelotas, rassier1907@gmail.com

${ }^{2}$ Medicina Veterinária, Universidade Federal de Pelotas, helenicegonzalez@ hotmail.com

${ }^{3}$ Medicina Veterinária, Universidade Federal de Pelotas, silvia.s.ladeira@ gmail.com

${ }^{4}$ Departamento de Ciência e Tecnologia Agroindustrial, Universidade Federal de Pelotas, dorsgi@yahoo.com.br

${ }^{5}$ Prof $^{a}$. Dr ${ }^{a}$. em Medicina Veterinária, Universidade Federal de Pelotas, pattsn@gmail.com
} 
Keywords: cattle, CMT, dairy production, milk quality, resistance.

\section{Introdução}

Cerca de 150 milhões de lares em todo mundo estão envolvidos na produção leiteira, impulsionados principalmente pelo retorno rápido que a atividade traz ao produtor (FAO, 2016). O leite é considerado um dos mais nobres alimentos devido a sua composição; rico em proteína, gordura, carboidratos, sais minerais e vitaminas, além de fornecer elementos anticarcinogênicos presente na gordura, como o ácido linoléico conjugado, esfingomielina, ácido butírico, beta-caroteno e vitaminas A e D (BITENCOURT et al., 2000; BRITO; BRITO, 2004). No Brasil, a produção leiteira está entre as atividades mais importantes dentro do setor agropecuário, responsável por grande relevância social e econômica (LUCCA \& AREND, 2020). Entretanto, o leite tem apresentado alguns problemas na sua qualidade, como a alta contagem de microrganismos encontrados no mesmo (NOEL et al., 2016; CARVALHO et al., 2018; TAPONEN et al., 2019).

Devido a seu alto teor nutritivo, qualquer descuido durante o processo de ordenha pode acarretar na presença de bactérias e consequentemente queda na qualidade do leite e de seus derivados (CERVA, 2013). Sabe-se que a carga microbiana inicial influencia na qualidade do leite, e quanto maior o número de contaminantes e a temperatura de estocagem, menor será o tempo de conservação do produto (SILVEIRA et al., 1998). A regularização das condições sanitárias para a industrialização do leite e seus derivados e os padrões físico-químicos e microbiológicos para que estes produtos possam ser liberados para o comércio varejista são estabelecidos pelas Instruções Normativas 76 e 77 (BRASIL, 2018a; BRASIL 2018b).

Do ponto de vista sanitário e comercial, a bovinocultura leiteira encontra sérios entraves principalmente pela alta prevalência de mastite, doença que prevalece dentro dos rebanhos bovinos destinados a produção leiteira, impactando negativamente na economia (LANGONI et al., 2011; ACOSTA et al., 2016). Os principais agentes relacionados a mastite são as bactérias gram-positivas, incluindo Staphylococcus aureus, Streptococcus agalactiae, e Mycoplasma bovis (SHAHEEN; TANTARY; NABI 2016), e seu aparecimento está relacionado, principalmente ao manejo inadequado de ordenha, já que os microrganismos relacionados as inflamações são geralmente originados da cama, fezes, urina, equipamento de ordenha e água (CUNHA et al.,2016).

A mastite subclínica possui incidência muito maior em um rebanho leiteiro comparada a mastite clínica, podendo apresentar prevalência de $20 \%$ em rebanhos de alta produção a 50\% em rebanhos de baixa produção (SHAHEEN et al., 2016; HOSSAIN et al., 2017). Neste caso 
não há sinais visíveis na forma subclínica, esta pode passar despercebida em muitos casos e o método mais utilizado para sua detecção é a Contagem de Células Somáticas (CCS) pelo California Mastits Test (CMT), por se tratar de um teste de baixo custo e fácil aplicação em rebanhos leiteiros (ROSSI et al., 2018).

O uso de antibióticos ainda é o procedimento mais utilizado dentro das salas de ordenha para o tratamento da mastite bovina, com o intuito de aumentar a produção e reduzir as fontes de infecção (SHAHEEN et al., 2016). Entretanto, a utilização indevida e indiscriminada destes fármacos sem avaliar sua eficácia pode contribuir para o aumento na resistência antimicrobiana dentro dos sistemas de produção (WHO, 2015). Além disso, eventualmente, resíduos de antimicrobianos utilizados na terapia da doença podem ser encontrados no leite (CADES et al., 2017). O antibiograma é um teste que oferece como resultado padrões de resistência ou sensibilidade de uma bactéria específica a vários antimicrobianos e a realização do antibiograma sempre indica os melhores antibióticos para o controle de determinada doença/infecção, visto que existem antibióticos específicos para o controle das diferentes bactérias (KONEMAN et al., 2012)

Neste contexto, considerando a importância da mastite para a qualidade do leite e consequente produção leiteira em nosso país e no mundo, o objetivo deste estudo foi testar a suscetibilidade de bactérias isoladas em casos de mastite subclínica frente a três antibióticos comumente utilizados para o tratamento de mastite bovina na medicina veterinária.

\section{Material e Métodos}

Foram selecionadas bactérias isoladas de amostras de leite colhidas em diferentes propriedades rurais do município de Pelotas - RS, a partir de tetos de animais que apresentaram mastite subclinica com resultados positivos $(++$ e +++ ) no teste de CMT (California Mastitis Test) (SCHALM, 1957). A coleta do leite com mastite foi realizada obtendo uma amostra de leite, cerca de $10 \mathrm{~mL}$ em tubos estéreis de teste individuais, sendo previamente realizada a identificação dos tubos e a desinfecção do orifício do teto com algodão embebido em álcool $70^{\circ} \mathrm{GL}$ e retirado os primeiros jatos. Os tubos foram acondicionados em caixas isotérmicas com gelo e remetidas sob refrigeração. As amostras de leite foram semeadas em Ágar Sangue, incubadas por 24 horas à temperatura de $36^{\circ} \mathrm{C}$ e identificadas no Laboratório Regional de Diagnóstico da Faculdade de Medicina Veterinária- UFPel e estocadas no Laboratorio de Inspecao de Produtos de Origem Animal (LIPOA) da mesma Universidade. A metodologia utilizada seguindo o manual de identificação bacteriana de Cowan e Steel (STEEL et al. 1993).

Após a realização da técnica de coloração de Gram, todas as amostras foram submetidas 
ao teste de Catalase para diferenciar Staphylococcus spp. (catalase positiva) de Streptococcus spp. (catalase negativa). As amostras positivas para catalase foram submetidas a MR-VP (vermelho de metila, Voges-Proskauer), teste de coagulase e análises bioquímicas utilizando ribose, nitrato, galactose, maltose, manitol e Trealose, além de resistência à polimixina. CAMP foi realizado para amostras negativas de catalase e testes de esculina, inulina, manitol, salicina, sorbitol e trealose. Após a realização dos testes, as amostras foram colocadas na estufa a $37^{\circ} \mathrm{C}$ e após 24 horas a leitura foi realizada.

Foram selecionados os microrganismos de maior frequência em mastite: nove Staphylococcus spp. coagulase negativa, seis Staphylococcus spp. coagulase positiva, sete Corynebacterium spp., quatro Streptococcus spp. não-hemolítico e um Streptococcus betahemolítico.

O antibiograma foi realizado pelo método de difusão em ágar Muller-Hillton, através da disposição de discos comerciais impregnados com os antibióticos: Amoxicilina + ácido Clavulânico, Gentamicina e Tetraciclina, em placas com o meio de cultivo, onde previamente foi semeado o agente bacteriano a ser testado (KIRBY \& BAUER, 1956).

Após a realização do procedimento as placas foram incubadas a $36^{\circ} \mathrm{C}$ por 24 horas. A leitura do antibiograma foi realizada através da medida dos halos formados ao redor dos discos com antibióticos (TRABULSI \& ALTERTHUM, 2004). O resultado foi expresso como: resistente (R), intermediário (I) ou sensível (S) aos antibióticos, interpretados de acordo com o CLSI (2012).

\section{Resultados e Discussão}

Foram selecionados Staphylococcus spp. coagulase negativa, Staphylococcus spp. coagulase positiva, Corynebacterium spp. e Streptococcus spp. e sua escolha foi baseada na frequência em que eles são descritos como principais agentes causadores de mastite subclínica (RIBEIRO et al., 2008; OLIVEIRA et al., 2011; KREWER et al., 2013; ACOSTA et al., 2016; SHAHEEN; TANTARY; NABI 2016; ZIMERMANN et al., 2017).

Quando se fala de mastite, S. aureus é o principal agente etiológico, sendo isolado em diferentes países no mundo, incluindo o Brasil (FREITAS et al., 2018; HOQUE et al., 2018; GEMECHU; YUNUS; SOMA \& BEYENE, 2019; MESQUITA et al., 2020). Este microrganismo se adapta facilmente a condições hostis, o que facilita sua colonização, dispersão e causar doenças. Além disso, apresentam diversos fatores de virulência, como proteína A, enzima e toxinas que contribuem para o estabelecimento da infecção (CEPEDA et al., 2005). No rebanho leiteiro, sua infecção caracteriza-se geralmente na forma subclínica, 
resultando em vacas contaminadas, aumento de células somáticas e difícil erradicação (BRITO \& BRITO, 1998).

Ainda que existam algumas características de virulência que contribuem para a persistência do $S$. aureus no tecido mamário, o uso inadequado de antibióticos propicia o aparecimento de cepas multirresistentes, comprometendo a eficiência do tratamento da mastite bovina causada por estes e outros microrganismos (CUNHA et al., 2006). No nosso estudo, não foi observada a presença de cepas multirresistentes.

Corynebacterium spp. está entre os principais agentes de mastite e embora possa ser encontrado em mastite clínica, normalmente está relacionado a infecções subclínicas (BRADLEY; GREEN, 2005; OLIVEIRA et al., 2011). São considerados patógenos contagiosos, responsáveis por elevar a contagem de células somáticas (NATIONAL MASTITIS COUNCIL, 2004).

Streptococcus uberis e $S$. dysgalactiae estão entre as principais espécies dentro do gênero Streptococcus, relacionadas a mastite subclínica (BI et al., 2016; WALD et al., 2020). S. uberis é um patógeno importante na indústria de laticínios (DIESER et al., 2017), visto que é um microrganismo comensal e assintomático, isolado de diversas partes do corpo de bovinos, como pele, intestino, amígdalas e trato genital (WARD et al., 2009). Streptococcus dysgalactiae também está entre os mais comuns microrganismos relacionados a mastites ambientais e embora sejam isolados a partir de tonsilas, boca e vagina de vacas, podem persistir nas glândulas mamárias e ser transmitidos de uma vaca para outra (QUINN et al., 2005).

A descrição da sensibilidade, resistência ou sensibilidade intermediária dos isolados frente à amoxicilina com ácido clavulânico $10 \mathrm{mcg}(\mathrm{A})$, a gentamicina 10mcg (B) e a tetraciclina $30 \mathrm{mcg}(\mathrm{C})$ estão descritos na tabela 1.

Tabela 1. Descrição da suscetibilidade dos isolados bacterianos obtidos de mastite bovina frente a três antibióticos: amoxicilina + ácido clavulânico 10mcg (A), gentamicina 10mcg (B) e tetraciclina 30mcg (C)

\begin{tabular}{llll}
\hline Isolados bacterianos & A & B & C
\end{tabular}

Staphylococcus spp. (coagulase negativa) (2)

$\begin{array}{lll}\text { S } & \text { S } & \text { S } \\ \text { S } & \text { S } & \text { S } \\ \text { S } & \text { S } & \text { S } \\ \text { S } & \text { S } & \text { I } \\ \text { S } & \text { S } & \text { I } \\ \text { S } & \text { S } & \text { I } \\ \text { S } & \text { I } & \text { S }\end{array}$


Corynebacterium sp. (1)

S R S

Staphylococcus spp. (coagulase positiva) (2)

S R S

Streptococcus sp. (não hemolítico) (1)

Staphylococcus sp. (coagulase negativa) (1)

Streptococcus beta-hemolítico (1)

Streptococcus sp. (não hemolítico) (1)

S R S

Staphylococcus sp. (coagulase negativa) (1)

S R I

S R I

S R I

Staphylococcus sp. (coagulase positiva) (1)

S R R

Staphylococcus sp. (coagulase negativa) (1)

S R R

Staphylococcus sp. (coagulase negativa) (1)

R $\quad \mathrm{S} \quad \mathrm{S}$

Corynebacterium sp. (4)

R $\quad \mathrm{S} \quad \mathrm{R}$

Streptococcus sp. (não hemolítico) (1)

R $\quad \mathrm{S} \quad \mathrm{R}$

R $\quad \mathrm{S} \quad \mathrm{R}$

*S - sensível; I - sensibilidade intermediária; R - resistente.

Fonte: Própria (2020)

Após avaliar a suscetibilidade das 27 bactérias frente aos três antibióticos, observou-se que a gentamicina (B) foi o antibiótico ao qual o maior número de isolados apresentaram resistência (37,1\%), resultado oposto ao observado por diversos trabalhos (CUNHA et al., 2006; DA SILVA et al., 2019; KUROSAWA et al., 2020). Cunha et al. (2006) avaliaram os perfis de sensibilidade, in vitro, de Staphylococcus sp., Corynebacterium sp., Streptococcus sp., E. coli, Bacillus sp., Micrococcus sp., Enterococcus sp. e Klebsiella sp. isoladas de mastite bubalina, e observaram que a gentamicina foi o antibiótico que demonstrou o maior percentual de eficácia com 97,98\% de inibição das amostras estudadas. Kurosawa et al. (2020) também obtiveram resultados que diferiram do nosso estudo após testarem a suscetibilidade de 29 amostras de Staphylococcus spp. oriundos de leite e observarem que apenas uma amostra se mostrou resistente $(3,24 \%)$ à gentamicina. No trabalho realizado por Da Silva et al. (2019) foi observada $100 \%$ de eficácia da gentamicina frente aos isolados de leite cru.

A resistência a tetraciclina (C) foi observada em $22,2 \%$ das bactérias testadas no nosso estudo. KUROSAWA et al. (2020) obtiveram resultados melhores do que o nosso, onde das 29 amostras de Staphylococcus spp. testadas, 24 foram sensíveis $(82,76 \%)$, um intermediário $(3,45 \%)$ e quatro resistentes $(13,90 \%)$. Da Silva et al. (2019) observaram 100\% de eficácia quando testaram a tetraciclina. Diferentemente, em estudo realizado por Cunha et al. (2006), a tetraciclina foi a droga que apresentou a menor eficácia in vitro, com 41,42\% dos microrganismos resistentes a este fármaco. De acordo com Zimermann \& Araújo (2017), alguns microrganismos apresentam uma proteína (Tet) que lhes confere resistência à tetraciclina 
através do transporte do antibiótico para fora da célula bacteriana.

No nosso estudo, o antibiótico que apresentou maior eficácia foi a amoxicilina + ácido clavulânico (A), com 81,5\% das amostras apresentando sensibilidade e 18,5\% das amostras apresentando resistência. Estes resultados concordaram com Trinidad et al. (1990) que estudando a susceptibilidade antimicrobiana de Staphylococcus aureus $(\mathrm{n}=48)$, Staphylococcus chromogenes $(\mathrm{n}=167)$, Staphylococcus hyicus $(\mathrm{n}=71)$ e outros Staphylococcus $\mathrm{sp} .(\mathrm{n}=17)$ isolados de mastite em novilhas e primíparas, testando a amoxicilina + ácido clavulânico obtiveram sensibilidade em 90,5\%, 100\%, 100\% e 100\% das amostras, respectivamente. Resultado diferente foi encontrado por Da Silva et al. (2019), quando 33,33\% das bactérias patogênicas isoladas de leite apresentaram resistência

As espécies resistentes a amoxicilina + ácido clavulânico foram dois Staphylococcus spp. coagulase negativa e três Corynebacterium spp. Frente a gentamicina, a resistência foi observada em dois Staphylococcus spp. coagulase negativa, três Staphylococcus spp. coagulase positiva, um Corynebacterium sp., três Streptococcus spp. não hemolíticos e um Streptococcus sp. beta hemolítico. Amoxicilina + ácido clavulânico foi o antibiótico ao qual a maior variabilidade de gêneros das bactérias identificadas neste estudo apresentou resistência. As espécies resistentes a tetraciclina foram três Staphylococcus spp. coagulase negativa, quatro Corynebacterium spp. e um Streptococcus sp. não hemolítico. Vale salientar que nenhum dos antibióticos testados apresentou $100 \%$ de eficácia.

Dentre as sete amostras de Corynebacterium spp. do nosso estudo, três $(42,85 \%)$ apresentaram resistência a amoxacilina + ácido clavulânico, uma (14,28\%) a gentamicina e três $(42,85 \%)$ a tetraciclina. Entre os cinco Streptococcus spp. (incluindo um hemolítico) houve resistência de quatro amostras (80\%) apenas frente a gentamicina. Dentro dos Staphylococcus spp. apenas três $(20 \%)$ apresentaram resistência somente a gentamicina. Os outros, quando apresentaram resistência, esta estava presente a mais de um antibiótico. Vários autores concordam que existe uma significativa diferença entre o perfil de sensibilidade a antimicrobianos entre Staphylococcus sp. e Streptococcus sp. (ANDRADE et al., 2000; CUNHA et al., 2006; POUTREL et al., 2018).

De modo geral, a resistência antimicrobiana está entre as dez principais ameaças a saúde global (OMS, 2019) e atualmente grande importância tem sido dada à multirresistência antibiótica das bactérias, por sua correlação com a presença de microrganismos virulentos, como os S. aureus meticilina-resistentes (MRSA) (BULLÉ, et al., 2016; SISTI, 2017; SILVA et al., 2018). S. aureus é a espécie mais frequentemente associada a casos e surtos de intoxicação alimentar, visto que algumas cepas são capazes de produzir várias enterotoxinas 
(EE) (OMOE et al., 2005).

$\mathrm{O}$ estabelecimento de alternativas para tratamento de mastites de origem infecciosa em vacas leiteiras é de grande importância e testes de suscetibilidade antimicrobiana como o realizado nesse trabalho auxiliam nisso (LANGONI et al., 2006). Vários métodos de tipagem bacteriana são utilizados para comparar cepas e identificar mecanismos de transmissão e fontes de contaminação, e dentro desses métodos o antibiograma tem sido usado por ser de fácil execução, acessível, permitir controle de qualidade rigoroso e de baixo custo, além de permitir o conhecimento acerca da resistência microbiana das bactérias testadas (RIBEIRO et al., 2008).

Uma alternativa para minimizar os riscos de contaminação por estes microrganismos dentro da bovinocultura leiteira é a aplicação de Boas Práticas de Produção (BPP) nas diferentes etapas do processo (VALLIN et al., 2009). Paschoal (2014) salienta que os equipamentos que auxiliam na ordenha podem contribuir com cerca de $10 \%$ da carga microbiana do leite em condições experimentais, podendo este valor aumentar caso a estrutura ou a limpeza dos equipamentos não estejam satisfatórias. Com relação aos equipamentos dentro da sala de ordenha, Gleeson et al. (2009) destacam as teteiras da ordenhadeira mecânica como a maior causa de contaminação entre as vacas, entretanto, o adequado manejo pré-ordenha pode reduzir a contaminação dos tetos não só por bactérias ambientais como também por bactérias provenientes de outros animais.

Além disso, as técnicas de pré e pós-dipping auxiliam na forma de preparar o teto para a ordenha. O pré-dipping significa a imersão dos tetos das vacas em uma solução desinfetante momentos antes da ordenha, responsável por queda de até 50\% na taxa de novas infecções da glândula mamária e consequentemente, diminuição do número de bactérias que entram em contato com o leite e passam pelas tubulações (FONSECA \& SANTOS, 2001; BLOWEY; EDMONDSON, 2010). Entretanto, a desinfecção ao final da ordenha (pós-dipping) é considerada a prática isolada mais importante de controle de novas infecções intramamárias, onde os melhores resultados estão relacionados ao uso de iodo, $0,7 \%$ a $1,0 \%$; clorexidina, $0,5 \%$ a $1,0 \%$ e cloro, $0,3 \%$ a $0,5 \%$ (FONSECA \& SANTOS, 2001).

Embora o controle de mastite tenha como principal fundamento a realização de medidas higiênico sanitárias, o uso de antibióticos tem um papel importante no combate de patógenos, principalmente os relacionados a mastite contagiosa, possibilitando a eliminação das infecções intramamárias e reduzindo as fontes de infecção (ERSKINE et al., 1993). Entretanto, seu uso deve ser com cautela, pois quando de forma descontrolada, o uso de antibióticos em animais para alimentação seleciona bactérias resistentes que podem chegar até os seres humanos pelo contato com os animais, contato direto e indireto com resíduos e/ou consumo de alimentos 
(GRACE, 2015; O’NEILL, 2015). Bactérias resistentes a agentes antimicrobianos, mesmo que não patogênicas, podem interferir de forma negativa para as futuras opções de tratamento (OVERDEVEST et al., 2011).

As drogas aqui testadas já foram amplamente empregadas no passado e o uso incorreto associado à seleção natural dos microrganismos provavelmente resultou no fenômeno de resistência. Embora a resistência a antimicrobianos possa ocorrer naturalmente por meio de mutações espontâneas, o uso intensivo de antimicrobianos em humanos e animais acaba acelerando o processo (WHO, 2015). Entre os mecanismos de resistência estão a produção de enzimas que destroem ou inativam as drogas, redução da permeabilidade celular, criação de rotas secundárias alternativas que substituem as inibidas pela droga, eliminação do antibiótico ou alteração do sitio-alvo da droga (QUINN et al., 2005).

Deve-se salientar que a escolha aleatória de medicamentos para tratamento de mastite nas propriedades leiteiras, não implicará obrigatoriamente no sucesso do tratamento, especialmente naquelas propriedades onde seu uso é frequente e inadequado (NADER et al., 2007). Além do mais, testes como o realizado nesse estudo auxiliam na preservação das bases antimicrobianas para que futuramente possam ser utilizadas com eficácia no controle de doenças/infecções, evitando a formação de resistência pelas bactérias e também promove um registro histórico de quais bactérias são resistentes em uma determinada propriedade aos variados antibióticos disponíveis, possibilitando assim, melhores medidas de controle.

\section{Conclusões}

Em decorrência da diversidade de agentes etiológicos envolvidos em mastites, a utilização de exames microbiológicos e posteriormente testes de sensibilidade antimicrobiana in vitro são medidas indicadas antes da eleição do tratamento, pois esta diversidade microbiológica pode ter diferentes respostas frente ao medicamento a ser utilizado, como vem se observando no decorrer dos anos. Além disso, o uso indiscriminado dos produtos para essa enfermidade vem aumentando a resistência desses agentes patógenos frente aos antibióticos de uso rotineiro.

\section{Referências}

ACOSTA, A. C. et al. Mastites em ruminantes no Brasil. Pesquisa Veterinária Brasileira, v. 36, n. 7, p. 565-573, 2016.

ANDRADE, M. A. et al. Sensibilidade in vitro de Staphylococcus aureus isolados de amostras de leite de vacas com mastite subclínica. 2000. 
BI, Yanliang et al. Prevalence of bovine mastitis pathogens in bulk tank milk in China. PLoS One, v. 11, n. 5, p. e0155621, 2016.

BITENCOURT, D. et al. Sistemas de pecuária de leite: uma visão na região de clima temperado. Pelotas: Embrapa Clima Temperado, 2000.

BLOWEY, R. W.; EDMONDSON, P. Mastitis control in dairy herds. Cabi, 2010.

BRADLEY, A.; GREEN, M. Use and interpretation of somatic cell count data in dairy cows. In practice, v. 27, n. 6, p. 310-315, 2005.

BRASIL. Ministério da Agricultura, Pecuária e Abastecimento (MAPA). Instrução Normativa n 76 de novembro de 2018. Diário Oficial [da] República Federativa do Brasil, Brasília, DF, nov. 2018a. Disponível em <https://www.in.gov.br/materia/lasset_publisher/Kujrw0TZC2Mb/content/id/52750137/do1-2018-11-30-instrucao-normativan-76-de-26-de-novembro-de-2018-52749894IN\%2076> Acesso em 07 ago. 2020.

BRASIL. Ministério da Agricultura, Pecuária e Abastecimento. Instrução Normativa n. 77, de 26 de novembro de 2018. Diário Oficial [da] República Federativa do Brasil, Brasília, DF, 30 nov. 2018b. Disponível em <https://www.in.gov.br/materia//asset_publisher/Kujrw0TZC2Mb/content/id/52750141/do1-2018-11-30-instrucao-normativan-77-de-26-de-novembro-de-2018-52749887> Acesso em 07 ago. 2020.

BRITO, J. R. F.; BRITO, M. A. V. P. Qualidade do leite brasileiro e os desafios para atendimento das exigências internacionais. ZOCCAL, et al. Leite: uma cadeia produtiva em transformação. Juiz de Fora: Embrapa Gado de Leite, p. 235-243, 2004.

BRITO, J. R. F.; BRITO, M. A. V. P. Programas de controle das mastites causadas por microrganismos contagiosos e do ambiente. Embrapa Gado de Leite-Documentos (INFOTECA-E), 1998.

BULLÉ, D. J. et al. Prevalência de Staphylococcus aureus meticilina resistentes em profissionais de saúde. Revista de Enfermagem da UFSM, v. 6, n. 2, p. 198-205, 2016.

CADES, M. et al. Perfil de resistência antimicrobiana de mastite bovina em propriedade leiteira no município de Monte Negro/RO. Revista Brasileira de Ciências da Amazônia/Brazilian Journal of Science of the Amazon, v. 6, n. 1, p. 15-20, 2017.

CARVALHO, A. S. S. et al. Susceptibilidade de Staphylococcus aureus isolados de leite cru a antibióticos comerciais. Ciência Animal Brasileira, v. 19, 2018.

CEPEDA, J. A. et al. Isolation of patients in single rooms or cohorts to reduce spread of MRSA in intensive-care units: prospective two centre study. The Lancet, v. 365, n. 9456, p. 295-304, 2005.

CERVA, C. Manual de boas práticas na produção de leite em propriedades de agricultura familiar do Rio Grande do Sul. Porto Alegre: FEPAGRO, 2013. 
CLSI (Clinical and Laboratory Standards Institute). Methods for Dilution Antimicrobial Susceptibility Tests for Bacteria that Grow Aerobically. 2012.

DA CUNHA, A. F. et al. Prevalência, etiologia e fatores de risco de mastite clínica em rebanhos leiteiros de Viçosa-MG. Acta Veterinaria Brasilica, v. 10, n. 1, p. 48-54, 2016.

CUNHA, A. P. et al. Perfil de sensibilidade antimicrobiana de agentes contagiosos e ambientais isolados de mastite clínica e subclínica de búfalas. Arquivos do Instituto Biológico, v. 73, n. 1, p. 17-21, 2006.

DA SILVA, R. T. et al. Perfil de sensibilidade a antimicrobianos de bactérias patogênicas humanas isoladas de leite cru. Revista do Instituto de Laticínios Cândido Tostes, v. 74, n. 3, p. 185-194, 2019.

DIESER, S. A. et al. Streptococcus uberis: In vitro biofilm production in response to carbohydrates and skim milk. Revista Argentina de Microbiología, v. 49, n. 4, p. 305-310, 2017.

ERSKINE, R. J. et al. Advances in the therapy for mastitis. Veterinary Clinics of North America: Food Animal Practice, v. 9, n. 3, p. 499-517, 1993.

FONSECA, L. F. L.; SANTOS, M. V. Qualidade do leite e controle de mastite. 2001.

FOOD AND AGRICULTURE ORGANIZATION OF THE UNITED NATIONS (FAO). Dairy Production and Products - Milk Production. Disponível em <http://www.fao.org/dairyproduction-products/en/\#.V3AZwbgrLIV> Acesso em 14 jun. 2020.

FREITAS, C. H. et al. Identification and antimicrobial suceptibility profile of bacteria causing bovine mastitis from dairy farms in Pelotas, Rio Grande do Sul. Brazilian Journal of Biology, v. 78, n. 4, p. 661-666, 2018.

GEMECHU, T. et al. Bovine mastitis: Prevalence, Isolation and identification of major bacterial pathogens in selected areas of Bench Maji Zone, Southwest Ethiopia. Journal of Veterinary Medicine and Animal Health, v. 11, n. 2, p. 30-36, 2019.

GLEESON, D. et al. Effect of pre-milking teat preparation procedures on the microbial count on teats prior to cluster application. Irish Veterinary Journal, v. 62, n. 7, p. 1-7, 2009.

GRACE, D. Review of evidence on antimicrobial resistance and animal agriculture in developing countries. 2015.

HOQUE, M. N. et al. Molecular characterization of Staphylococcus aureus strains in bovine mastitis milk in Bangladesh. International Journal of Veterinary Science and Medicine, v. 6, n. 1, p. 53-60, 2018.

HOSSAIN, M. K. et al. Bovine mastitis and its therapeutic strategy doing antibiotic sensitivity test. Austin J Vet Sci Anim Husb, v. 4, n. 1, p. 1030, 2017.

KIRBY, W. M. et al. Clinical usefulness of a single disc method for antibiotic sensitivity testing. Antibiotics annual, 1956. 
KONEMAN, E. et al. Diagnóstico microbiológico: textos e atlas coloridos. 6 ed. Rio de Janeiro: Guanabara Koogan. 2012.

KREWER, C. C. et al. Etiology, antimicrobial susceptibility profile of Staphylococcus spp. and risk factors associated with bovine mastitis in the states of Bahia and Pernambuco. Pesquisa Veterinária Brasileira, v. 33, n. 5, p. 601-606, 2013.

KUROSAWA, L. S. et al. Perfil de susceptibilidade antimicrobiana de Staphylococcus spp. associados a mastite bovina. PUBVET, v. 14, p. 138, 2020.

LANGONI, H.; DOMINGUES, P. F.; BALDINI, S. Mastite caprina: seus agentes e sensibilidade frente a antimicrobianos. Revista Brasileira de Ciência Veterinária, v. 13, n. 1, 2006.

LANGONI, H. et al. Aspectos microbiológicos e de qualidade do leite bovino. Pesquisa Veterinária Brasileira, v. 31, n. 12, p. 1059-1065, 2011.

LUCCA, E. J.; AREND, S. C. A pecuária leiteira e o desenvolvimento da Região Noroeste do Rio Grande do Sul. Revista Brasileira de Desenvolvimento Regional, v. 7, n. 3, p. 107-142, 2020.

MESQUITA, A. A. et al. prevalência e resistência a antibióticos de Staphylococcus aureus e Streptococcus agalactiae em propriedades de agricultura familiar em rebanhos leiteiros de minas gerais, brasil. 2020.

NADER FILHO, A. et al. Sensibilidade antimicrobiana dos Staphylococcus aureus isolados no leite de vacas com mastite. Arquivos do Instituto Biológico, São Paulo, v. 74, n. 1, p. 14, 2007.

National Mastitis Council. Microbiological Procedures for the Diagnosis of Bovine Udder Infection and Determination of Milk Quality. Verona, USA. 47p. 2004.

DA COSTA NOEL, C. et al. Perfil de suscetibilidade antimicrobiana e produção de "slime" de isolados de Staphylococcus spp. provenientes de casos de mastite bovina na região sulfluminense. Revista de Saúde, v. 7, n. 1, p. 22-26, 2016.

O'NEILL J. Antimicrobials in agriculture and the environment: reducing unnecessary use and waste. London, UK: Review on Antimicrobial Resistance, 2015.

OLIVEIRA, C. M. C. et al. Prevalência e etiologia da mastite bovina na bacia leiteira de Rondon do Pará, estado do Pará. Pesquisa Veterinária Brasileira, v. 31, n. 2, p. 104-110, 2011.

OMOE, K. et al. Comprehensive analysis of classical and newly described staphylococcal superantigenic toxin genes in Staphylococcus aureus isolates. FEMS microbiology letters, v. 246, n. 2, p. 191-198, 2005.

ORGANIZAÇÃO MUNDIAL DA SAÚDE. Thirteenth general programme of work 2019-2023. Disponível em <https://www.who.int/about/what-we-do/thirteenth-generalprogramme-of-work-2019---2023>. Acesso em 04 jun. 2020. 
OVERDEVEST, I. et al. Extended-spectrum $\beta$-lactamase genes of Escherichia coli in chicken meat and humans, The Netherlands. Emerging infectious diseases, v. 17, n. 7, p. 1216, 2011.

PASCHOAL, J. J. Qualidade do Leite. In: SILVA, J. C. P. M. et al. (Ed.). Manejo e Administração na Bovinocultura Leiteira. Viçosa, p. 181-198. 2014.

POUTREL, B. et al. Prevalence of mastitis pathogens in France: Antimicrobial susceptibility of Staphylococcus aureus, Streptococcus uberis and Escherichia coli. J Vet Sci Technol, v. 9, n. 522, p. 2, 2018.

QUINN, P. J. et al. Microbiologia veterinária e doenças infecciosas. Artmed Editora, 2005.

RIBEIRO, M. G. Princípios terapêuticos na mastite em animais de produção e de companhia. Manual de Terapêutica Veterinária. $3^{\text {a }}$ ed. Roca, São Paulo, p. 759-771, 2008.

ROSSI, R. S. et al. Diagnostic accuracy of Somaticell, California Mastitis Test, and microbiological examination of composite milk to detect Streptococcus agalactiae intramammary infections. Journal of dairy science, v. 101, n. 11, p. 10220-10229, 2018.

SCHALM, O. W. Experiments and observations leading to development of the California Mastitis Test. J. Am. Vet. Med. Assoc., v. 130, p. 199-204, 1957.

SHAHEEN, M.; TANTARY, H. A.; NABI, S. U. A treatise on bovine mastitis: disease and disease economics, etiological basis, risk factors, impact on human health, therapeutic management, prevention and control strategy. Advances in Dairy Research, p. 1-10, 2016.

SILVA, J. G.; ALCÂNTARA, A. M.; MOTA, R. A. Mastite bovina causada por Staphylococcus spp. resistentes à meticilina: revisão de literatura. Pesquisa Veterinária Brasileira, v. 38, n. 2, p. 223-228, 2018.

SILVEIRA, I. A. da; CARVALHO, E. P. de; TEIXEIRA, D. Influência de microrganismos psicrotróficos sobre a qualidade do leite refrigerado: uma revisäo. Hig. aliment, p. 21-7, 1998.

SISTI, E. A relevância do staphylococcus aureus resistente à meticilina (MRSA) nas infecções hospitalares. REVISTA INTERDISCIPLINAR DE ENSINO, PESQUISA E EXTENSÃO-RevInt, v. 4, n. 1, 2017.

STEEL, K. J., BARROW, G.I., FELTHAM, R.K.A. Cowan and Steel's manual for the identification of medical bacteria. Cambridge university press. 1993.

TAPONEN, S. et al. Bovine milk microbiome: a more complex issue than expected. Veterinary research, v. 50, n. 1, p. 44, 2019.

TRABUlSI, L. R.; ALTERTHUM, F. Microbiologia. 4ed. São Paulo: Atheneu, 2004.

TRINIDAD, P.; NICKERSON, S. C.; ALLEY, T. K. Prevalence of intramammary infection and teat canal colonization in unbred and primigravid dairy heifers. Journal of Dairy

Science, v. 73, n. 1, p. 107-114, 1990. 
VALLIN, V. M. et al. Melhoria da qualidade do leite a partir da implantação de boas práticas de higiene na ordenha em 19 municípios da região central do Paraná. Semina: Ciências Agrárias, v. 30, n. 1, p. 181-188, 2009.

WALD, R. et al. Comparison of the population structure of Streptococcus uberis mastitis isolates from Austrian small-scale dairy farms and a Slovakian large-scale farm. Journal of Dairy Science, v. 103, n. 2, p. 1820-1830, 2020.

WARD, P. N. et al. Evidence for niche adaptation in the genome of the bovine pathogen Streptococcus uberis. BMC genomics, v. 10, n. 1, p. 1-17, 2009.

WHO 2015. World Health Organization. Antibiotic resistance. Disponível em <https://www.who.int/ > . Acesso 2 jun. 2020.

ZAATOUT, N.; AYACHI, A.; KECHA, M. Epidemiological investigation of subclinical bovine mastitis in Algeria and molecular characterization of biofilm-forming Staphylococcus aureus. Tropical Animal Health and Production, v. 52, n. 1, p. 283-292, 2020.

ZIMERMANN, K. F.; ARAUJO, M. E. M. Mastite bovina: agentes etiológicos e susceptibilidade a antimicrobianos. Campo Digital, v. 12, n. 1, 2017. 